\title{
Rationale, Design and Methodology of the Computerized Registry of Patients with Venous Thromboembolism (RIETE)
}

\author{
Behnood Bikdeli ${ }^{1,2}$ David Jimenez ${ }^{3} \quad$ Mayra Hawkins $^{4}$ Salvador Ortíz ${ }^{5}$ Paolo Prandoni ${ }^{6}$ \\ Benjamin Brenner $^{7}$ Hervé Decousus ${ }^{8}$ Frederick A. Masoudi ${ }^{9}$ Javier Trujillo-Santos ${ }^{10}$ \\ Harlan M. Krumholz ${ }^{2,11}$ Manuel Monreal ${ }^{12}$ for the RIETE Investigators
}

${ }^{1}$ Division of Cardiology, Department of Medicine, Columbia University Medical Center/New York-Presbyterian Hospital, New York, New York, United States

${ }^{2}$ Center for Outcomes Research and Evaluation (CORE), Yale University School of Medicine, New Haven, CT, USA

${ }^{3}$ Department of Respiratory, Hospital Ramón y Cajal, Universidad de Alcalá (IRYCIS), Madrid, Spain

${ }^{4}$ RIETE Registry Coordinating Center, S \& H Medical Science Service, Madrid, Spain

${ }^{5}$ Department of Statistics, Universidad Autónoma de Madrid, S \& H Medical Science Service, Madrid, Spain

6 Vascular Medicine Unit, Department of Cardiovascular Sciences, University of Padua, Padua, Italy

${ }^{7}$ Department of Haematology and Bone Marrow Transplantation, Rambam Health Care Campus, Haifa, Israel

8 Department of Vascular Medicine and Therapeutics, Hôpital Nord - CHU St-Etienne, Saint-Etienne, France

${ }^{9}$ Division of Cardiology, Department of Medicine, University of Colorado Anschutz Medical Campus, Aurora, Colorado, United States

10 Department of Internal Medicine, Hospital General Universitario Santa Lucía. Murcia, Spain

11 Section of Cardiovascular Medicine, Department of Internal Medicine, Yale University School of Medicine, New Haven, Connecticut, United States

${ }^{12}$ Department of Internal Medicine, Hospital Universitari Germans Trias i Pujol, Badalona, Barcelona, Spain
Address for correspondence Manuel Monreal, MD, PhD, Hospital Universitari Germans Trias i Pujol, 08916 Badalona, Barcelona, Spain (e-mail: mmonreal.germanstrias@gencat.cat).

\footnotetext{
Thromb Haemost 2018;118:214-224.
}

\begin{abstract}
\section{Keywords}

- venous thrombosis

- deep vein thrombosis

- pulmonary embolism
\end{abstract}

Venous thromboembolism (VTE), including deep vein thrombosis (DVT) and pulmonary embolism (PE), is a preventable cause of in-hospital death, and one of the most prevalent vascular diseases. There is a lack of knowledge with regards to contemporary presentation, management and outcomes of patients with VTE. Many clinically important subgroups (including the elderly, those with recent bleeding and pregnant patients) have been underrepresented in clinical trials. Furthermore, design of clinical trials is challenging in some scenarios, such as in those with hemodynamically unstable PE. RIETE (Registro Informatizado Enfermedad TromboEmbolica) is a large prospective multinational ongoing registry, designed to address these unmet needs using representative data from multiple centres. Initiated in Spain in 2001, RIETE currently includes 179 centres in 24 countries and has enrolled more than 72,000 patients. RIETE has helped characterize the pattern of received

July 25, 2017

accepted after revision

September 15, 2017
DOI https://doi.org/ 10.1160/TH17-07-0511. ISSN 0340-6245. 
presentation and outcomes of VTE, including the aforementioned understudied subgroups. RIETE has recently expanded to collect long-term outcome data, and has broadened its inclusion criteria to enrol other forms of venous thrombosis (such as cerebral vein thrombosis and splanchnic vein thrombosis). The RIETE platform is also being used to conduct pragmatic comparative effectiveness studies, including randomized trials. Future steps would focus on collaboration with additional centres across the world, and efforts to ensure the quality and expansion of the registry. In conclusion, RIETE is a large ongoing registry of patients with VTE and other thrombotic conditions. Its results could be helpful for improving our understanding of the epidemiology, patterns of care and outcomes of patients with thrombotic disease.

\section{Introduction}

Venous thromboembolism (VTE) is an important preventable cause of in-hospital death. ${ }^{1-3}$ VTE including deep vein thrombosis (DVT) and pulmonary embolism (PE) afflicts an estimated $1,000,000$ new cases annually in Europe and the United States, combined. ${ }^{4-6}$ Among survivors, VTE is associated with recurrent events, post-thrombotic syndrome, pulmonary hypertension and bleeding events (as a result of anticoagulant therapy), all of which contribute to the high burden of the disease. ${ }^{7,8}$

However, contemporary aspects of VTE presentation, pattern of care, and outcomes are understudied. Published epidemiological studies are generally limited by small size, data age (representing a different era of diagnosis and treatment) (10 $^{9,10}$ or lack of detailed clinical data. ${ }^{11,12}$ Clinical trials have also faced challenges in providing adequate evidence base, with ethical and feasibility issues limiting recruitment for some important conditions (e.g. PE with hemodynamic instability, or VTE among those with recent bleeding), ${ }^{13}$ and underrepresentation of many key subgroups (such as the elderly, pregnant patients, and those with high risk of bleeding) that limit the availability and generalizability of the evidence. These issues have led to a growing unmet imperative for evidence from large groups of patients without numerous exclusions. ${ }^{14}$ Contemporary information to characterize the modern-day presentation, risk factor profile, treatment and outcomes of patients can inform practice and policy, preventing unnecessary harm, and bringing novel hypotheses for future research and improving quality and outcomes. ${ }^{15-18}$

The Registro Informatizado Enfermedad TromboEmbolica (RIETE) is a large prospective registry initiated to address these unmet needs and has been enrolling patients with objectively confirmed VTE since 2001. Several of the resultant studies have provided a better understanding of the epidemiology, ${ }^{19,20}$ common treatment patterns, ${ }^{21,22}$ and outcomes ${ }^{23,24}$ of patients with VTE and the key understudied clinical subgroups. ${ }^{25-27}$ In response to continued and expanding investigations from RIETE, herein we provide an overview of the design, methodology, possible and future directions of the registry.

\section{Methods}

RIETE is an ongoing, prospective multicentre multinational observational study of patients with objectively confirmed acute VTE. The registry was originally started in Spain in 2001 with the goal of gathering a large sample of patients with VTE, with specific attention to those excluded from the typical randomized trials of anticoagulant therapy (e.g. those with severe renal insufficiency, liver failure, recent major bleeding, pregnancy, disseminated cancer, thrombocytopenia and the elderly) with an aim to understand their common presentation, management pattern and outcomes, as well as factors associated with better or worse patient outcomes. The hope was also to use the hypothesis-generating findings to help design new randomized clinical studies.

With successful recruitment of an increasing number and diversity of patients over time, the numbers of retrieved variables and data elements were progressively increased. The platform, including the electronic data entry system, was translated to English from 2006 and the network expanded to other participating centres. As of June 30, 2017, RIETE includes 207 investigators from 179 participating centres. RIETE is registered at Clinicaltrials.gov (NCT: 02832245). Detailed information about participating centres is also available at the registry Web site: https://www.riete.org/.

\section{Patients, Inclusion and Exclusion Criteria}

At each participating site, patients are screened by the site investigators and checked for eligibility (-Table 1). All patients are objectively confirmed with acute symptomatic or asymptomatic VTE (i.e. DVT, PE, or both). More recently, in an attempt to similarly understand the presentation, treatment pattern, and outcomes of other thrombotic conditions, RIETE has also started to enrol patients with superficial vein thrombosis, splanchnic vein thrombosis (i.e. thrombosis involves the mesenteric, splenic or portal veins), retinal vein thrombosis and cerebral vein thrombosis. At each participating centre, every attempt is made to enrol consecutive patients and RIETE investigators are committed, by contract agreement, to enrol consecutive patients. Periodic audits of the sites have confirmed consecutiveness. Further, comparison against the Spanish Ministry of Health database has shown that patients in RIETE have similar characteristics to the data from all-comers with VTE in that database. ${ }^{28}$ No duplicate entries are permitted and patients who are enrolled in blinded treatment trials are ineligible.

Methods of DVT diagnosis include contrast venography, ultrasonography, magnetic resonance or, rarely in the past, 
Table1 Inclusion and exclusion criteria for RIETE

\begin{tabular}{|l|}
\hline Inclusion criteria \\
\hline $\begin{array}{l}\text { Acute objectively confirmed DVT or acute objectively } \\
\text { confirmed PE }\end{array}$ \\
\hline $\begin{array}{l}\text { Availability of data for at least } 54 \text { core variables and } \\
\text { minimum of 3-mo follow-up }\end{array}$ \\
\hline Exclusion criteria \\
\hline $\begin{array}{l}\text { Enrolment in any treatment trial } \\
\text { (VTE or other conditions) } \\
\text { in a blinded fashion }\end{array}$ \\
\hline Previous enrolment in the registry \\
\hline Lack or withdrawal of patient consent \\
\hline
\end{tabular}

Abbreviations: DVT, deep vein thrombosis; PE, pulmonary embolism; RIETE, Registro Informatizado Enfermedad TromboEmbolica (also known as the Computerized Registry of Patients with Venous Thromboembolism); VTE, venous thromboembolism. ${ }^{a}$ Not mutually exclusive (i.e. patients may have both DVT and PE but will not be double counted).

b In more recent years, those with superficial vein thrombosis, splanchnic vein thrombosis (i.e. thrombosis involves thrombosis in the mesenteric, splenic or portal veins), retinal vein thrombosis and cerebral vein thrombosis have been separately enrolled.

plethysmography (only 172 patients in the entire cohort). PE is diagnosed on the basis of pulmonary angiography, contrast-enhanced computed tomography (CT) of the chest (specifically CT pulmonary angiography), lung scintigraphy or rarely on the basis of confirmed DVT in patients with signs and symptoms of PE.

RIETE, by design, does not currently enrol patients with intracardiac thrombi in the absence of VTE. As of 30 June 2017, a total of 72,107 valid patients with acute VTE have been enrolled in RIETE. Currently, RIETE has 179 participating sites from 24 countries and across 3 continents. There has been a growth, over time, in the number of involved sites and countries (-Fig. 1A, B).

\section{Data Elements}

Key data elements in RIETE include demographics, VTE risk factors and comorbidities (such as presence or absence of immobility, hormonal therapies, pregnancy and puerperal state, recent surgery, active cancer, heart failure, chronic lung disease, renal and liver function, prior VTE, prior bleeding episodes, dementia, depression, autoimmune disorders, gastroduodenal ulcer, inflammatory bowel disease and others). It also includes concomitant medications (such as antiplatelet agents, corticosteroids, nonsteroidal anti-inflammatory drugs, erythropoietin, statins and psychotropic drugs) and disposition status (inpatient vs. outpatient). Test results (common blood tests [including plasma haematocrit, platelet count, creatinine and others], cardiac biomarkers [including troponin, CK-MB and B-type natriuretic peptide], electrocardiography [including the rhythm, presence of right bundle branch block, S1Q3T3 patter and others], ultrasonography, echocardiography, CT scan) and therapies (including antithrombotic medications and advanced therapies such as thrombolytic therapy, surgical thrombectomy and inferior vena caval filter placement; - Table 2) are separately recorded.

\section{Outcomes}

The main outcomes of interest in RIETE include all-cause death, PE-specific death, recurrent DVT, recurrent PE, major bleeding, non-major (but clinically relevant) bleeding, arterial ischemic events (myocardial infarction, ischemic stroke or leg amputation), thrombocytopenia, bone fractures and other side-effects of the prescribed therapies. In recent years, development of post-thrombotic syndrome (since 2008) and chronic thromboembolic pulmonary hypertension (since 2015) are also ascertained in those with reported longterm follow-up ( - Table 3). RIETE, by design, does not require universal screening for asymptomatic events.

\section{Follow-up}

The minimum follow-up duration for patients in RIETE is at least 3 months. ${ }^{13}$ Since 2010 , collaborators have been requested to extend follow-up to at least 12 months. As for June 302017 , a total of 24,828 patients have followed up for at least 12 months and 11,304 for at least 24 months (-Fig. 2).

\section{Ethics}

All enrolees provide written or verbal informed consent according to the local ethics protocols of enrolling centres. The institutional review board at each enrolling centre approves participation in RIETE for the site investigators and allows the entry of de-identified patient information into the RIETE database.

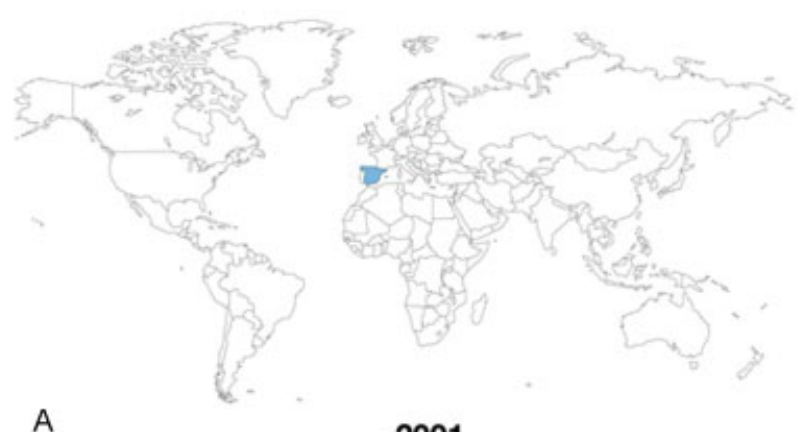

2001

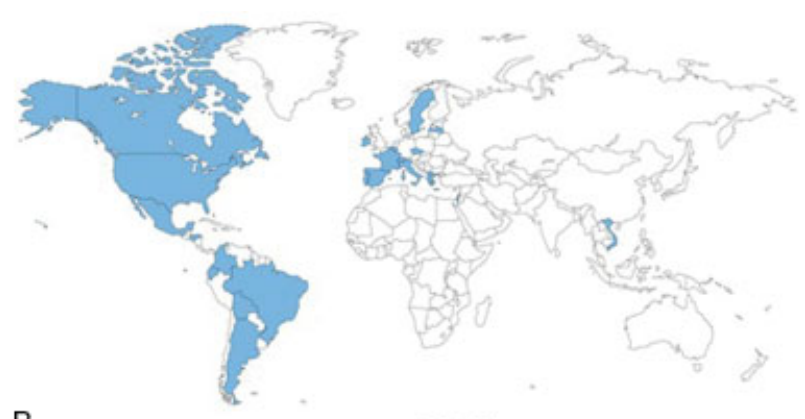

2017

Fig. 1 Participating countries in RIETE in 2001 (A) and 2017 (B). 
Table 2 Select list of data elements

\begin{tabular}{|c|c|c|c|c|c|}
\hline & $\begin{array}{l}\text { Patients with } \\
\text { available } \\
\text { values }(N)\end{array}$ & DVT cohort & PE cohort & Other patients ${ }^{a}$ & Total \\
\hline Patients (\%) & 72,107 & 33,150 & 35,745 & 3,212 & $72,107(100 \%)$ \\
\hline $\begin{array}{l}\text { Disposition } \\
\text { (inpatient vs. outpatient) }\end{array}$ & 70,122 & $8,228(25.5 \%)$ & $10,872(31.3 \%)$ & $794(25.4 \%)$ & $19,894(28.4 \%)$ \\
\hline \multicolumn{6}{|l|}{ Demographics } \\
\hline Male (\%) & 72,107 & $17,019(51.3 \%)$ & $16,668(46.6 \%)$ & $1,684(52.4 \%)$ & $35,371(49.1 \%)$ \\
\hline Age $(y \pm S D)$ & 72,107 & $63.5 \pm 18$ & $67.3 \pm 17$ & $63.5 \pm 15.4$ & $65.4 \pm 17.5$ \\
\hline Body mass index $\left(\mathrm{kg} / \mathrm{m}^{2}\right)$ & 50,118 & $27.6 \pm 5.2$ & $28.2 \pm 5.7$ & $27 \pm 5.2 \ddagger$ & $27.8 \pm 5.5$ \\
\hline \multicolumn{6}{|l|}{ Underlying conditions } \\
\hline Chronic lung disease & 72,107 & $2,800(8.4 \%)$ & $5,112(14.3 \%)$ & $326(10.1 \%)$ & $8,238(11.4 \%)$ \\
\hline Chronic heart failure & 72,107 & $1,455(4.4 \%)$ & $3,263(9.1 \%)$ & $137(4.3 \%)$ & $4,855(6.7 \%)$ \\
\hline Diabetes & 45,033 & $2,778(14.8 \%)$ & $3,693(16 \%)$ & $585(18.7 \%)$ & $7,056(15.7 \%)$ \\
\hline Hypertension & 45,263 & $8,117(43 \%)$ & $11,869(51 \%)$ & $1,409(44.9 \%)$ & $21,395(47.3 \%)$ \\
\hline Prior myocardial infarction & 45,002 & $1,224(6.5 \%)$ & $1,918(8.3 \%)$ & $176(5.7 \%)$ & $3,318(7.4 \%)$ \\
\hline Prior ischemic stroke & 44,981 & $1,095(5.8 \%)$ & $1,800(7.8 \%)$ & $170(5.5 \%)$ & $3,065(6.8 \%)$ \\
\hline Recent major bleeding & 72,107 & $678(2 \%)$ & $836(2.3 \%)$ & $125(3.9 \%)$ & $1,639(2.3 \%)$ \\
\hline Anaemia & 72,107 & $11,883(35.8 \%)$ & $11,680(32.7 \%)$ & $1,410(43.9 \%)$ & $24,973(34.6 \%)$ \\
\hline Platelet count $<150,000$ & 71,990 & $885(2.7 \%)$ & $823(2.3 \%)$ & $144(4.6 \%)$ & $1,852(2.6 \%)$ \\
\hline Platelet count $>450,000$ & 71,990 & $1,113(3.4 \%)$ & $1,264(3.5 \%)$ & $155(4.9 \%)$ & $2,532(3.5 \%)$ \\
\hline Recent surgery & 72,107 & $3,476(10.5 \%)$ & $4,241(11.9 \%)$ & $316(9.8 \%)$ & $8,033(11.1 \%)$ \\
\hline Recent immobility & 72,107 & $7,530(22.7 \%)$ & $7,642(21.4 \%)$ & $464(14.4 \%)$ & $15,636(21.7 \%)$ \\
\hline Active cancer & 72,107 & $7,655(23.1 \%)$ & $7,974(22.3 \%)$ & $1,612(50.2 \%)$ & $17,241(23.9 \%)$ \\
\hline Prior VTE & 72,107 & $5,336(16.1 \%)$ & $5,258(14.7 \%)$ & $272(8.5 \%)$ & $10,866(15.1 \%)$ \\
\hline Pregnancy/Puerperium & 72,107 & $561(1.7 \%)$ & $314(0.9 \%)$ & $31(1 \%)$ & $906(1.3 \%)$ \\
\hline Hormonal use & 72,107 & $1,779(5.4 \%)$ & $1,916(5.4 \%)$ & $158(4.9 \%)$ & $3,853(5.3 \%)$ \\
\hline \multicolumn{6}{|l|}{ Initial therapy } \\
\hline Low-molecular-weight heparin & 72,107 & $30,634(92.4 \%)$ & $30,138(84.3 \%)$ & $2,504(78 \%)$ & $63,276(87.8 \%)$ \\
\hline Unfractionated heparin & 72,107 & $877(2.6 \%)$ & $3413(9.5 \%)$ & $94(2.9 \%)$ & $4,384(6.1 \%)$ \\
\hline Fondaparinux & 72,107 & $736(2.2 \%)$ & $613(1.7 \%)$ & $92(2.9 \%)$ & $1,441(2 \%)$ \\
\hline NOACs & 20,792 & $579(7.1 \%)$ & $417(4 \%)$ & $35(1.6 \%)$ & $1,031(5.0 \%)$ \\
\hline Thrombolytic therapy & 72,107 & $54(0.2 \%)$ & $882(2.5 \%)$ & $3(0.1 \%)$ & $939(1.3 \%)$ \\
\hline Vena cava filter use & 72,107 & $720(2.2 \%)$ & $1,042(2.9 \%)$ & $80(2.5 \%)$ & $1,842(2.6 \%)$ \\
\hline \multicolumn{6}{|l|}{ Clinical presentation } \\
\hline SBP levels $<90 \mathrm{~mm} \mathrm{Hg}$ & 69,286 & $268(0.9 \%)$ & $1,253(3.5 \%)$ & $37(1.3 \%)$ & $1,558(2.2 \%)$ \\
\hline Syncope & 69,108 & $195(0.6 \%)$ & $5,211 Z(15 \%)$ & $46(1.6 \%)$ & $5,452(7.9 \%)$ \\
\hline Heart rate $\geq 110 \mathrm{~mm} \mathrm{Hg}$ & 67,212 & $1,374(4.6 \%)$ & $7,272(21 \%)$ & $169(6.1 \%)$ & $8,815(13.1 \%)$ \\
\hline Sat $\mathrm{O}_{2}$ levels <90\% & 27,097 & $289(6.9 \%)$ & $6,618(29.6 \%)$ & $64(12 \%)$ & $6,971(25.7 \%)$ \\
\hline
\end{tabular}

Abbreviations: DVT, deep vein thrombosis; NOAC, non-vitamin K antagonist oral anticoagulant; PE, pulmonary embolism; VTE, venous thromboembolism.

Note: Data include patients enrolled until 30 June 2017.

${ }^{a}$ Those with superficial vein thrombosis, splanchnic vein thrombosis (i.e. thrombosis involves thrombosis in the mesenteric, splenic or portal veins), retinal vein thrombosis and cerebral vein thrombosis. 
Table 3 Main study outcomes and their definitions

\begin{tabular}{|l|l|}
\hline Outcomes & Definition \\
\hline All-cause mortality & $\begin{array}{l}\text { Autopsy-confirmed. In the absence of autopsy, fatal PE is defined as any death appearing within } \\
10 \mathrm{~d} \text { after symptomatic PE diagnosis, in the absence of any alternative cause of death }\end{array}$ \\
\hline PE-specific mortality & $\begin{array}{l}\text { Recurrent DVT is defined as a new non-compressible vein segment, or an increase of the vein } \\
\text { diameter of }>4 \text { mm compared with the last available measurement on venous ultrasono- } \\
\text { graphy. Recurrent PE is defined as a new ventilation-perfusion mismatch on lung scan or a new } \\
\text { intraluminal filling defect on spiral computed tomography or pulmonary angiography }\end{array}$ \\
\hline Recurrent VTE & $\begin{array}{l}\text { Bleeding events that are overt and required a transfusion of two units or more of blood, or are } \\
\text { retroperitoneal, spinal or intracranial, or when they are fatal }\end{array}$ \\
\hline $\begin{array}{l}\text { Major bleeding } \\
\text { non-major bleeding }\end{array}$ & $\begin{array}{l}\text { Bleeding events that are overt and require medical assistance but not fulfilling criteria for } \\
\text { major bleeding }\end{array}$ \\
\hline Fatal bleeding & $\begin{array}{l}\text { Any death occurring within 10 d of a major bleeding episode, in the absence of an alternative } \\
\text { cause of death }\end{array}$ \\
\hline Post-thrombotic syndrome & Evaluated every 12 mo according to the Villalta score \\
\hline $\begin{array}{l}\text { Chronic thromboembolic } \\
\text { pulmonary hypertension }\end{array}$ & $\begin{array}{l}\text { Diagnosed by site investigators based on assessment of clinical information and tests } \\
\text { including echocardiography, ventilation-perfusion lung scan, pulmonary angiography, } \\
\text { pulmonary functional tests and right heart catheterization }\end{array}$ \\
\hline Bone fractures & Confirmed by adequate image testing \\
\hline Myocardial infarction & $\begin{array}{l}\text { Presence of typical chest pain in combination with a transient increase of creatine kinase-MB or } \\
\text { troponin and/or typical electrocardiographic signs (development of pathologic Q-waves or } \\
\text { ST-segment elevation or depression) that are not otherwise explained }\end{array}$ \\
\hline Arterial ischemic events & $\begin{array}{l}\text { Diagnosed in the setting of acute neurological event not resolving completely within 24 hours, } \\
\text { confirmed by computed tomography or magnetic resonance imaging }\end{array}$ \\
\hline
\end{tabular}

Abbreviations: PE, pulmonary embolism; VTE, venous thromboembolism.

Note: Outcomes are assessed in various time intervals including during the inpatient stay, 30 days after the event, 3 months after the even and longer term in a subset of patients with available data.

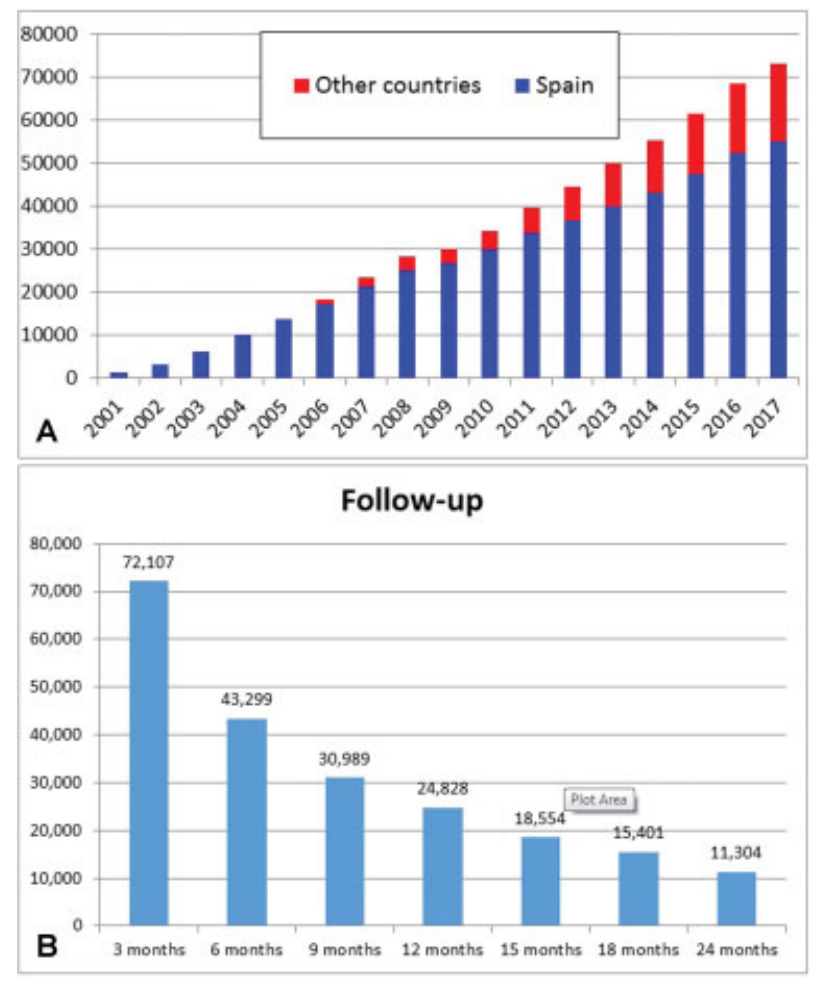

Fig. 2 Cumulative number of enrolled patients over time. The topfive recruiting countries are Spain $(n=54,525)$, Italy $(n=5,910)$, France $(n=4,233)$, Israel $(n=2,650)$ and Switzerland $(n=1,144)$. (A) Cumulative number of enrolled patients over time. (B) Amount of patients followed-up for $>3,6,9,12,15,18$ and 24 months.

\section{Data Entry}

Data are entered into electronic case report forms through an electronic portal and submitted to the coordinating centre via secure Web site ${ }^{13}$ (- Fig. 3, https://www.riete.org/login.php).

\section{Quality Control and Oversight}

S \& H Medical Science Service serves as the coordinating centre for RIETE. The study coordinating centre assigns a unique identification number for each patient to avoid duplicate entries and ensure the security of protected health information. The coordinating centre ensures the completeness of data entry by site investigators. In order for a patient to count in the registry, a minimum of 54 core data elements (variables) related to the first 3 months of care need to be completed. Of the main items in these 54 elements, age, gender, weight, date of diagnosis, recent major bleeding, characteristics of DVT/PE (diagnostic method), risk factors (cancer, surgery, immobilization, history of DVT/PE, pregnancy), laboratory (haemoglobin, leukocytes, platelets), clinical symptoms, treatments (drug, dose, onset and finishing date), IVC filter use (yes/no and timing), date of last follow-up and events (death, thromboembolic recurrence, bleeding) could be named. The number of variables has been progressively increasing over the years. Recently, depending on the events, ancillary tests, therapies and follow-up duration, each patient may be represented by up to 1,000 variables filled out; yet as discussed earlier, there are only 54 core mandatory variables per patient. Data quality is electronically monitored by S \& H Medical Science Service on 

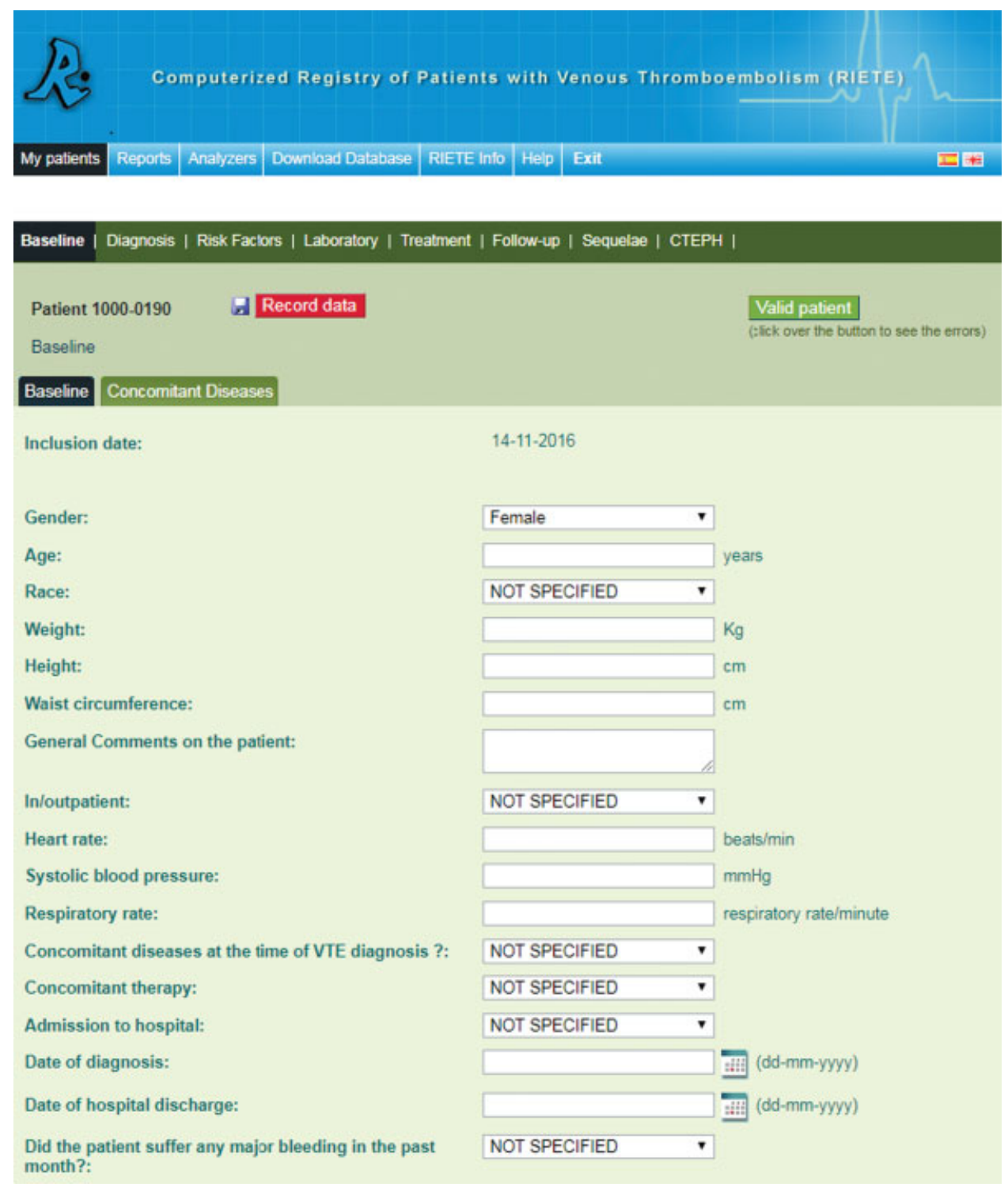

Fig. 3 Screenshot from the electronic data entry platform.

a weekly basis. In case of identification of several inconsistencies from any enrolling centre, a full audit of all the data from that centre is performed. In addition, trained staffs from $S \& H$ Medical Science Service make periodic visits to participating centres and compare the information in a randomly selected sample of patients entered by the site investigators. In the most recent audit, RIETE staff assessed 4,100 randomly chosen records that included 1,230,000 measurements. The data showed 95\% overall agreement between the registered information by site investigators and patients' original records (with no difference between key data elements and others, and no specific patterns that undermined a group of variables disproportionately). The audits also included ascertainment of inclusion of consecutive patients via cross-checking by available medical records at enrolling hospitals. The RIETE leadership and steering committee (led by Dr. Monreal) is in charge of overseeing the registry, ensuring the collaboration between the investigators and the S \& H Medical Science Service, and proposing, soliciting and overseeing the process for develop- ment, and publication of new research projects based on RIETE. All active members are permitted to propose new studies. The proposals are reviewed by the leadership and steering committee and, if not overlapping with prior or ongoing projects, would be enlisted.

\section{Statistical Analysis}

A dedicated team of statisticians conducts the statistical analyses. The main data warehouse for RIETE is in Madrid, Spain, and managed by $S$ \& H Medical Science Service. RIETE analyses are either performed by statisticians at the S \& H Medical Science Service or by other RIETE statisticians who have signed confidentiality contracts and downloaded de-identified portions of the data into secure platforms. Patients whose entered data do not fulfil the minimum available variables criteria will not be entered in any of the analyses. Categorical variables are reported as frequencies and percentages. Continuous variables are reported as means with standard deviation. Tests of comparison, association, survival analysis, multivariable 
adjustment, propensity-score matching and others are contingent on hypotheses and questions per each individual study from the RIETE database. Large numbers would enable the investigators to explore the regional variations, and to determine the robustness of analyses by factors such as sites and volume. Multi-level modelling could help minimize errors related to potential clustering of observations, if one occurs at certain centres. Although RIETE does not have a study-wide statistical approach for missing data (e.g. multiple imputations), the coordinating centre makes study-wide efforts to help minimize missing data elements by frequent communications with each of the enrolling centres.

\section{Discussion}

RIETE is a large multicentric multinational registry of patients with acute VTE. Over the past 15 years, it has provided data for more than 100 original research studies, some of which have been among the seminal studies related to epidemiology, prognostication or comparative effectiveness of strategies for management of VTE. ${ }^{19,21,29-31}$ Investigations from RIETE have provided novel information about VTE risk factors, therapies and outcomes among understudied subgroups such as pregnant patients, those at high risk of bleeding, those with morbid obesity and the elderly persons. ${ }^{25,26,32,33}$ Other studies revealed distinct risk gradients across key subgroups, including differential presentation and outcomes based on primary cancer site. ${ }^{34}$ Some others provided evidence from observational studies in areas where randomized trials are extremely difficult to conduct, if not impossible, including for those with VTE and high bleeding risk, ${ }^{24,35}$ or patients with PE and hypotension. ${ }^{23}$ RIETE investigators have also contributed to studies related to prognostication, including for the simplified PE severity index. ${ }^{29}$ Other studies have shown the contemporary trends in hospitalizations, clinical presentation and outcomes of patients with DVT and with PE.21,22 With continued enrolment and increase in the number and diversity of collaborating centres, in part via better recognition of the registry by other investigators and in part by active advocacy from existing RIETE investigators and the steering committee, it is expected that the registry continues to provide a greater breadth and depth of information related to presentation, treatment pattern and outcomes of patients with VTE.

There are several functions in the usage of registries for cardiovascular conditions ${ }^{15-17}$ including VTE. Registries enable us to look into VTE epidemiology (including hospitalizations, and in many cases outpatients), common treatment patterns, trends, variations in practice and also to address some questions related to comparative effectiveness, especially in areas where randomized trials are unfeasible or unlikely to occur (including efficacy studies related to the oldest old, patients with morbid obesity or severe renal insufficiency, or for conditions where equipoise is questioned because of existing grandfathered therapies, or where enrolment is technically challenging because of the high acuity of medical illness [such as the case of massive PE, disseminated cancer and others]; - Table 4). ${ }^{36-42}$ Registry data complement the findings from randomized trials and are a critical element for contemporary knowledge generation, and quality control. Findings can reflect on routine practice results for newly approved or existing health interventions and may unravel new signals for benefits or harms that were previously understudied in randomized trials. Further, they can reflect on variations in care, temporal trends over time and adherence to guidelines recommendations, among many other utilities.

RIETE encompasses several distinct features ${ }^{18}$ compared with other existing and ongoing VTE registries. ${ }^{10,36-38,42}$ The large sample size (to our knowledge, the largest prospective patient-level VTE registry) enables the investigators to study questions that are not feasibly addressed in single-centre studies. ${ }^{19,21,29-31}$ Patient enrolment is from many centres with various levels of acuity of care, making it a representative sample and providing opportunities for evaluation of care in ambulatory setting, general hospitals, and centres of excellence. Other future specific areas of interest include (but are not limited to) identification of risk factor profiles related to VTE recurrence that can help determine the duration of anticoagulation, and identification of factors based on VTE presentation and comorbidities that could provide hints at tailored therapy for specific drugs, doses and duration (which would be subsequently tested in trial platforms). RIETE also plans to provide additional empiric evidence on non-vitamin-K antagonist oral anticoagulants. Although such patients are currently under-represented in the registry, in part because of slow uptake of this class in Spain due to reimbursement issues, with increasing enrolment of patients from the rest of the world, and possibility of adjustments in the reimbursement regulations in Spain, we anticipate that the breadth and depth of data related to this class of medications in RIETE will be further enriched. The registry also aims to pay attention to understudied subgroups of patients such as those with splanchnic vein thrombosis, superficial vein thrombosis and others. RIETE is gaining additional information to help better characterize the significance and risk factor profile for long-term complications, such as post-thrombotic syndrome and chronic thromboembolic pulmonary hypertension. Furthermore, unlike several other registries, continuation of the registry over time makes it possible for assessment of temporal trends. Finally, the platform will also bring possibilities for future patient-oriented research investigations related to VTE, including pragmatic intervention trials, ${ }^{43}$ and quality improvement initiatives. In fact, some such randomized trials are under way using the RIETE platform. ${ }^{44-46}$ In large part driven by the data from the RIETE and tools created based on original such data, RIETE investigators have also created Web site that provides information related to VTE for physicians and patients, including risk estimation models (http://trombo.info/?lang=en). Also, contrary to some of the other existing registries, despite receiving funding from various groups, RIETE is independently investigator driven. The data are entirely managed by the investigators. The funders (including industry funders) have no rights in reviewing the protocols, abstracts or manuscripts, or about decisions to submit them. 


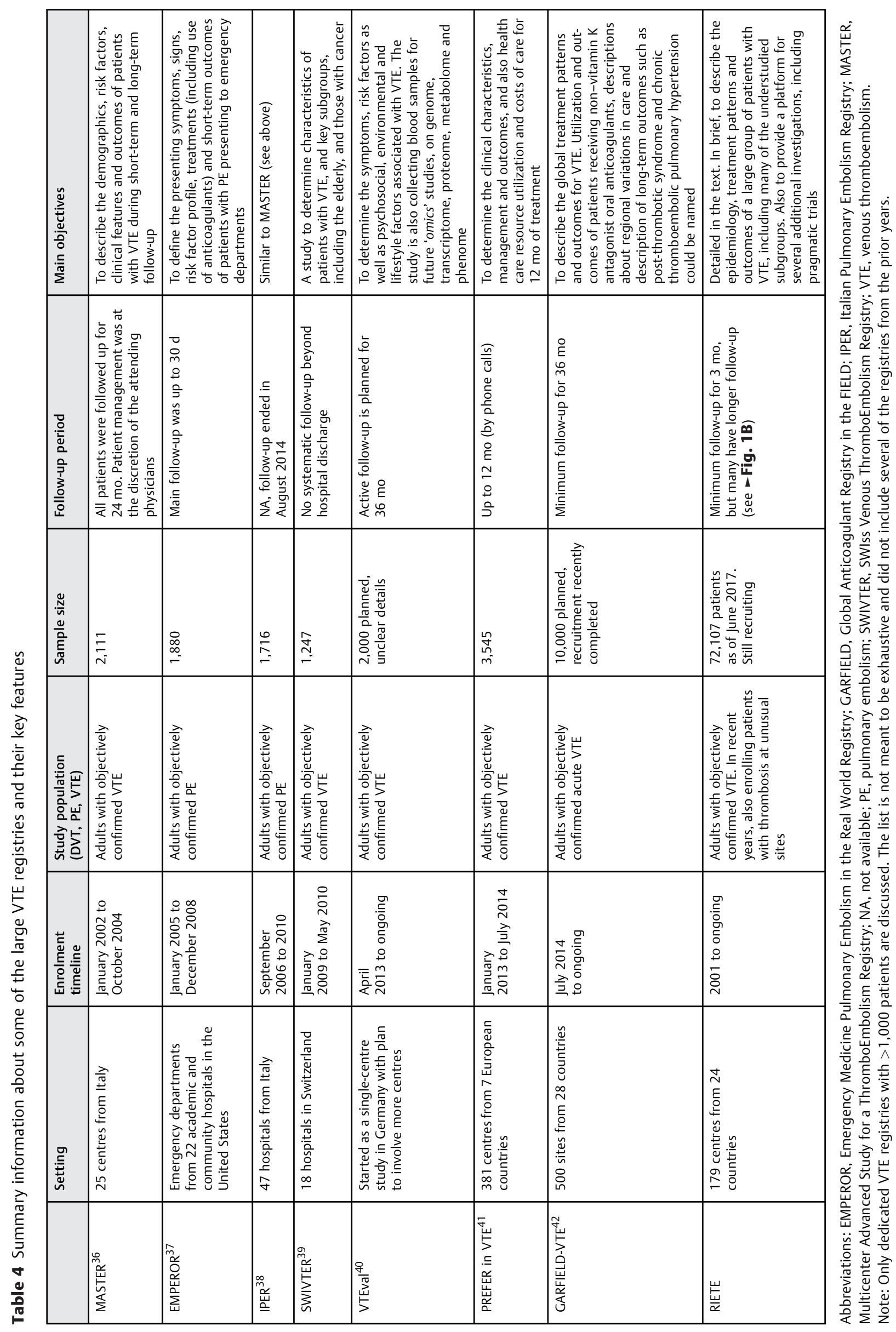


In conclusion, RIETE is a large existing and ongoing VTE registry. It is expected that RIETE will continue to provide clinical evidence for understudied subgroups with thrombotic disease, and will have more prominent role for facilitation of multicentre (and multinational studies) that could be used for assessment of variations and disparities in care, quality improvement and conducting comparative effectiveness research. The overarching goal is to improve the management of VTE through better understanding of prevention, as well as demographics, comorbidities, treatment patterns and outcomes of patients with VTE.

\section{Source of Funding and Its Roles}

RIETE is an investigator-initiated registry. During the first 5 years, it was supported by Red Respira from the Instituto Carlos III, Spain (Red Respira-ISCiii-RTIC-03/11). ${ }^{13}$ It has been also supported by Sanofi Spain in Spain and by Bayer Pharma AG for the rest of the world. There is no payment per recruited patient. The main incentive for patients and investigators participating in RIETE is to generate new knowledge to help for better understanding of VTE epidemiology and outcomes. None of the sponsors have had any role in the design of the registry and do not have rights to access the database, or to review or comment on prepublished studies from RIETE.

\section{Acknowledgments}

We express our gratitude to Sanofi Spain for supporting this Registry with an unrestricted educational grant. We also express our gratitude to Bayer Pharma AG for supporting this Registry. Bayer Pharma AG's support was limited to the part of RIETE outside Spain, which currently accounts for a $24.45 \%$ of the total patients included in the RIETE Registry. We also thank Silvia Galindo, S \& H Medical Science Service, for the statistical analysis of the data presented in this paper. We are grateful to the RIETE investigators who are the driving force of this registry, and patients who agreed and continue to agree to participate in RIETE without whose support this work would have never been possible. Dr. Bikdeli is supported by the National Heart, Lung, and Blood Institute, National Institutes of Health, through grant number T32 HL007854. The content is solely the responsibility of the authors and does not necessarily represent the official views of the NIH.

\section{References}

1 Wendelboe AM, Raskob GE. Global burden of thrombosis: epidemiologic aspects. Circ Res 2016;118(09):1340-1347

2 Geerts WH, Bergqvist D, Pineo GF, et al. Prevention of venous thromboembolism: American College of Chest Physicians Evidence-Based Clinical Practice Guidelines (8th Edition). Chest 2008;133:381S-453S

3 Bikdeli B, Sharif-Kashani B. Prophylaxis for venous thromboembolism: a great global divide between expert guidelines and clinical practice? Semin Thromb Hemost 2012;38(02):144-155

4 Heit JA, Cohen AT, Anderson FJ. Estimated annual number of incident and recurrent, non-fatal and fatal venous thromboembolism (VTE) events in the US. Blood 2005;106:267A
5 Cohen AT, Agnelli G, Anderson FA, et al; VTE Impact Assessment Group in Europe (VITAE). Venous thromboembolism (VTE) in Europe. The number of VTE events and associated morbidity and mortality. Thromb Haemost 2007;98(04):756-764

6 Bikdeli B, Bikdeli B. Updates on advanced therapies for acute pulmonary embolism. Int J Cardiovasc Pract 2016;1(3)

7 Kearon C, Akl EA, Comerota AJ, et al. Antithrombotic therapy for VTE disease: Antithrombotic Therapy and Prevention of Thrombosis, 9th ed: American College of Chest Physicians EvidenceBased Clinical Practice Guidelines. Chest 2012;141:e419S-e496S

8 Jaff MR, McMurtry MS, Archer SL, et al; American Heart Association Council on Cardiopulmonary, Critical Care, Perioperative and Resuscitation; American Heart Association Council on Peripheral Vascular Disease; American Heart Association Council on Arteriosclerosis, Thrombosis and Vascular Biology. Management of massive and submassive pulmonary embolism, iliofemoral deep vein thrombosis, and chronic thromboembolic pulmonary hypertension: a scientific statement from the American Heart Association. Circulation 2011;123(16):1788-1830

9 Stein PD, Henry JW. Clinical characteristics of patients with acute pulmonary embolism stratified according to their presenting syndromes. Chest 1997;112(04):974-979

10 Goldhaber SZ, Visani L, De Rosa M. Acute pulmonary embolism: clinical outcomes in the International Cooperative Pulmonary Embolism Registry (ICOPER). Lancet 1999;353(9162):1386-1389

11 Minges KE, Bikdeli B, Wang Y, et al. National trends in pulmonary embolism hospitalization rates and outcomes for adults aged $\geq 65$ years in the United States (1999 to 2010). Am J Cardiol 2015;116(09):1436-1442

12 Park B, Messina L, Dargon P, Huang W, Ciocca R, Anderson FA. Recent trends in clinical outcomes and resource utilization for pulmonary embolism in the United States: findings from the nationwide inpatient sample. Chest 2009;136(04):983-990

13 Tzoran I, Brenner B, Papadakis M, Di Micco P, Monreal M. VTE Registry: What can be learned from RIETE? Rambam Maimonides Med J 2014;5(04):e0037

14 Sherman RE, Anderson SA, Dal Pan GJ, et al. Real-world evidence What is it and what can it tell us? N Engl J Med 2016;375(23): 2293-2297

15 Gitt AK, Bueno H, Danchin N, et al. The role of cardiac registries in evidence-based medicine. Eur Heart J 2010;31(05):525-529

16 Bhatt DL, Drozda JP Jr, Shahian DM, et al. ACC/AHA/STS statement on the future of registries and the performance measurement enterprise: a report of the American College of Cardiology/ American Heart Association Task Force on Performance Measures and The Society of Thoracic Surgeons. J Am Coll Cardiol 2015; 66(20):2230-2245

17 Bufalino VJ, Masoudi FA, Stranne SK, et al; American Heart Association Advocacy Coordinating Committee. The American Heart Association's recommendations for expanding the applications of existing and future clinical registries: a policy statement from the American Heart Association. Circulation 2011;123(19):2167-2179

18 Monreal M, Mahé I, Bura-Riviere A, et al. Pulmonary embolism: epidemiology and registries. Presse Med 2015;44(12, Pt 2): e377-e383

19 Laporte S, Mismetti P, Décousus H, et al; RIETE Investigators. Clinical predictors for fatal pulmonary embolism in 15,520 patients with venous thromboembolism: findings from the Registro Informatizado de la Enfermedad TromboEmbolica venosa (RIETE) Registry. Circulation 2008;117(13):1711-1716

20 Lecumberri R, Soler S, Del Toro J, et al; RIETE Investigators. Effect of the time of diagnosis on outcome in patients with acute venous thromboembolism. Findings from the RIETE Registry. Thromb Haemost 2011;105(01):45-51

21 Jiménez D, de Miguel-Díez J, Guijarro R, et al; RIETE Investigators. Trends in the management and outcomes of acute pulmonary embolism: analysis from the RIETE Registry. J Am Coll Cardiol 2016;67(02):162-170 
22 Morillo R, Jiménez D, Aibar MA, et al; RIETE Investigators. DVT management and outcome trends, 2001 to 2014. Chest 2016; 150(02):374-383

23 Riera-Mestre A, Jiménez D, Muriel A, et al; RIETE Investigators. Thrombolytic therapy and outcome of patients with an acute symptomatic pulmonary embolism. J Thromb Haemost 2012; 10(05):751-759

24 Jiménez D, Muriel A, Monreal M, Yusen RD. Reply: immortal time bias and the use of IVC filters. J Am Coll Cardiol 2014; 64(09):955-956

25 López-Jiménez L, Montero M, González-Fajardo JA, et al; RIETE Investigators. Venous thromboembolism in very elderly patients: findings from a prospective registry (RIETE). Haematologica 2006;91(08):1046-1051

26 Blanco-Molina A, Rota LL, Di Micco P, et al; RIETE Investigators. Venous thromboembolism during pregnancy, postpartum or during contraceptive use. Thromb Haemost 2010;103(02): 306-311

27 Lobo JL, Nieto JA, Zorrilla V, et al; RIETE Investigators. Venous thromboembolism in patients with intracranial haemorrhage. Thromb Haemost 2011;106(04):750-752

28 Guijarro R, Montes J, Sanromán C, Monreal M; RIETE Investigators. Venous thromboembolism in Spain. Comparison between an administrative database and the RIETE registry. Eur J Intern Med 2008;19(06):443-446

29 Jiménez D, Aujesky D, Moores L, et al; RIETE Investigators. Simplification of the pulmonary embolism severity index for prognostication in patients with acute symptomatic pulmonary embolism. Arch Intern Med 2010;170(15):1383-1389

30 Trujillo-Santos J, Schellong S, Falga C, et al; RIETE Investigators. Low-molecular-weight or unfractionated heparin in venous thromboembolism: the influence of renal function. Am J Med 2013;126(05):425-434.e1

31 Mellado M, Pijoan JI, Jiménez D, et al; RIETE Investigators. Outcomes associated with inferior vena cava filters among patients with thromboembolic recurrence during anticoagulant therapy. JACC Cardiovasc Interv 2016;9(23):2440-2448

32 Nieto JA, De Tuesta AD, Marchena PJ, et al; RIETE Investigators. Clinical outcome of patients with venous thromboembolism and recent major bleeding: findings from a prospective registry (RIETE). J Thromb Haemost 2005;3(04):703-709

33 Barba R, Marco J, Martín-Alvarez H, et al; RIETE Investigators. The influence of extreme body weight on clinical outcome of patients with venous thromboembolism: findings from a prospective registry (RIETE). J Thromb Haemost 2005;3(05):856-862
34 Mahé I, Chidiac J, Bertoletti L, et al; RIETE Investigators. The clinical course of venous thromboembolism may differ according to cancer site. Am J Med 2017;130(03):337-347

35 Muriel A, Jiménez D, Aujesky D, et al; RIETE Investigators. Survival effects of inferior vena cava filter in patients with acute symptomatic venous thromboembolism and a significant bleeding risk. J Am Coll Cardiol 2014;63(16):1675-1683

36 Agnelli G, Verso M, Ageno W, et al; MASTER Investigators. The MASTER registry on venous thromboembolism: description of the study cohort. Thromb Res 2008;121(05):605-610

37 Pollack CV, Schreiber D, Goldhaber SZ, et al. Clinical characteristics, management, and outcomes of patients diagnosed with acute pulmonary embolism in the emergency department: initial report of EMPEROR(Multicenter Emergency Medicine Pulmonary Embolism in the Real World Registry). J Am Coll Cardiol 2011; 57(06):700-706

38 Casazza F, Becattini C, Bongarzoni A, et al. Clinical features and short term outcomes of patients with acute pulmonary embolism. The Italian Pulmonary Embolism Registry (IPER). Thromb Res 2012;130(06):847-852

39 Spirk D, Husmann M, Hayoz D, et al. Predictors of in-hospital mortality in elderly patients with acute venous thrombo-embolism: the SWIss Venous ThromboEmbolism Registry (SWIVTER). Eur Heart J 2012;33(07):921-926

40 Frank B, Ariza L, Lamparter H, et al; VTEval study group. Rationale and design of three observational, prospective cohort studies including biobanking to evaluate and improve diagnostics, management strategies and risk stratification in venous thromboembolism: the VTEval Project. BMJ Open 2015;5(07):e008157

41 Agnelli G, Gitt AK, Bauersachs R, et al; PREFER in VTE Investigators. The management of acute venous thromboembolism in clinical practice - study rationale and protocol of the European PREFER in VTE Registry. Thromb J 2015;13:41

42 Weitz JI, Haas S, Ageno W, et al. Global Anticoagulant Registry in the Field - Venous Thromboembolism (GARFIELD-VTE). Rationale and design. Thromb Haemost 2016;116(06):1172-1179

43 Lauer MS, D'Agostino RB Sr. The randomized registry trial-the next disruptive technology in clinical research? N Engl J Med 2013;369(17):1579-1581

44 The AINEP trial: EudraCT Public Web site. Available at: https:// eudract.ema.europa.eu/. Accessed July 5, 2017

45 The Slice Trials (NCT02238639). Available at: https://clinicaltrials. gov. Accessed July 5, 2017

46 The IPEP Trial. Available at: https://clinicaltrials.gov/ct2/show/ NCT02733198. Accessed September 1, 2017 


\section{Appendix A}

\section{Coordinator of the RIETE Registry:}

Dr. Manuel Monreal (Spain).

RIETE Steering Committee Members:

Dr. Hervè Decousus (France).

Dr. Paolo Prandoni (Italy).

Dr. Benjamin Brenner (Israel).

RIETE National Coordinators:

Dr. Raquel Barba (Spain).

Dr. Pierpaolo Di Micco (Italy).

Dr. Laurent Bertoletti (France).

Dr. Inna Tzoran (Israel).

Dr. Abilio Reis (Portugal).

Dr. Henri Bounameaux (Switzerland).

Dr. Radovan Malý (Czech Republic).

Dr. Philip Wells (Canada).

Dr. Peter Verhamme (Belgium).

Dr. Marijan Bosevski (Republic of Macedonia).

Dr. Joseph A. Caprini (United States).

RIETE Registry Coordinating Centre:

S \& H Medical Science Service.

\section{Appendix B}

Members of the RIETE Group:

Spain: Adarraga MD, Aibar MA, Alfonso M, Arcelus JI, Ballaz A, Baños P, Barba R, Barrón M, Barrón-Andrés B, Bascuñana J, Blanco-Molina A, Camon AM, Carrasco C, Cruz AJ, de Miguel J, del Pozo R, del Toro J, Díaz-Pedroche MC, DíazPeromingo JA, Falgá C, Fernández-Capitán C, FernándezMuixi J, Fidalgo MA, Font C, Font L, Furest I, García MA, García-Bragado F, García-Morillo M, García-Raso A, GarcíaSánchez AI, Gavín O, Gómez C, Gómez V, González J, Grau E,
Guijarro R, Gutiérrez J, Hernando E, Isern V, Jara-Palomares L, Jaras MJ, Jiménez D, Jiménez R, Joya MD, Lima J, Llamas $P$, Lobo JL, López-Jiménez L, López-Reyes R, López-Sáez JB, Lorente MA, Lorenzo A, Loring M, Lumbierres M, Madridano O, Maestre A, Marchena PJ, Martín M, Martín-Martos F, Mestre B, Monreal M, Morales MV, Nieto JA, Núñez MJ, Olivares MC, Otero R, Pedrajas JM, Pellejero G, Pérez-Ductor C, Peris ML, Pons I, Porras JA, Riera-Mestre A, Rivas A, Rodríguez-Dávila MA, Rosa V, Rubio CM, Ruiz-Artacho $P$, Sahuquillo JC, Sala-Sainz MC, Sampériz A, Sánchez-Martínez R, Sancho T, Soler S, Soto MJ, Suriñach JM, Tolosa C, Torres MI, Trujillo-Santos J, Uresandi F, Usandizaga E, Valero B, Valle R, Vela J, Vidal G, Villalobos A, Xifre B.

Argentina: Vázquez FJ, Vilaseca A.

Belgium: Vanassche T, Vandenbriele C, Verhamme P.

Brazil: Yoo HHB.

Canada: Wells P.

Czech Republic: Hirmerova J, Malý R.

Ecuador: Salgado E.

France: Benzidia I, Bertoletti L, Bura-Riviere A, Falvo N, Farge-Bancel D, Hij A, Merah A, Mahé I, Moustafa F, Quere I. Israel: Braester A, Brenner B, Ellis M, Tzoran I.

Italy: Bilora $\mathrm{F}$, Brandolin B, Bucherini E, Camerota A, Cattabiani C, Ciammaichella M, Dentali F, Di Micco P, Giorgi-Pierfranceschi M, Grandone E, Imbalzano E, Lessiani G, Maida R, Mastroiacovo D, Pace F, Pesavento R, Pinelli M, Prandoni P, Quintavalla R, Rocci A, Siniscalchi C, Tiraferri E, Visonà $\mathrm{A}$, Zalunardo $\mathrm{B}$.

Latvia: Gibietis V, Kigitovica D, Skride A.

Republic of Macedonia: Bosevski M, Zdraveska M.

Switzerland: Bounameaux H, Erdmann A, Fresa M, Mazzolai L.

United States: Bikdeli B, Caprini J. 